\section{Serving “a la CAR-T": Value-Based Pricing and Gene Therapy}

Like the rest of you, I've been pretty excited about the promise of chimeric antigen receptor T-cell (CAR-T) therapy and was thrilled when Novartis received FDA approval for CAR-T treatment in acute lymphoblastic leukemia. Genetically modifying our own immune cells to fight cancer is something that we all thought should be possible, but it took an intimate understanding of the immune system to finally get it right. Of course, we all hope that this technology can be transported to other diseases, especially solid tumors. This approval should renew interest (and funding) in research and development for CAR-T treatment and other cell-based therapies.

Yet, as excited as I am about the scientific breakthrough, I'm equally intrigued by the payment model introduced by Novartis. Of course, we would expect a big price tag for a treatment like this. It's cumbersome and involves referring patients to special centers. As with bone marrow transplant, peripheral blood mononuclear cells must be harvested, but then - unlike any other treatment - these cells are genetically modified and reintroduced. There is a lot of complexity, but the stakes are also high. This treatment is for children and young adults who experience relapse after standard treatment and face a death sentence.

So when I heard the price tag of $\$ 475,000$, I wasn't surprised. And yet it didn't seem too bad to me. After all, what's a life worth? I think it's a lot more than $\$ 475,000$. After all, if a little kid got lost in the forest, we'd spare no expense for search and rescue, right? But with CAR-T therapy, the price is even better, because if it doesn't work, it's free!

Value-based pricing related to outcome is not a new concept, although adoption has been slow. To see such a breakthrough therapy introduced with this type of pricing model kind of blows my mind. I think it's fantastic, and I applaud Novartis for taking a leadership role. My sincere hope is that this will set a standard for future drug pricing across the board.

We all know the cost of care is outrageous and out of control. For other types of products and services, we insist on getting good value and often a warranty. If your new vacuum cleaner shorts out, you return it and get your money back, with no questions asked. I think a similar model in healthcare would do a lot to curb cost. So let's watch this initiative carefully. And let's hope we're on the right track.

What do you think? Please e-mail correspondence (include contact information) to JNCCN@nccn.org or log into www.editiorialmanager.com/JNCCN to submit a Letter to the Editor.

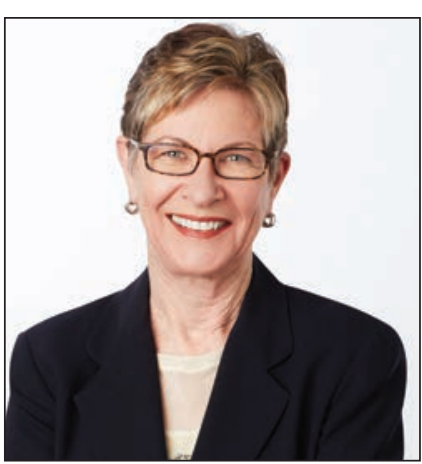

Margaret Tempero, MD

Margaret Tempero, MD, is a Professor of Medicine and Director of the UCSF Pancreas Center and editor-in-chief of JNCCN. Her research career has focused on pancreatic ductal adenocarcinoma, especially in the area of investigational therapeutics. Dr. Tempero has served on the ASCO Board of Directors and as ASCO President. She currently serves on the ASCO Conquer Cancer Foundation Board. She codirected the AACR/ASCO Methods in Clinical Cancer Research and taught this course and similar courses in Europe and Australia. She was founding Chair of the $\mathrm{NCl}$ Clinical Oncology Study Section and served as a member and Chair of the NCl Board of Scientific Counselors Subcommittee A. She is a member of the Scientific Steering Committee and Chair of the Clinical and Translational Study Section for the Cancer Prevention \& Research Institute of Texas. She is or has been on the Scientific Advisory Boards of the Lustgarten Foundation, the Pancreatic Cancer Action Network, the $V$ Foundation, The Alberta Canada Cancer Board, and the EORTC. She served as a member of the Oncology Drug Advisory Committee for the FDA. She has served as Deputy Director and Interim Director for the UNMC Eppley Cancer Center. She is Chief Emeritus of the Division of Medical Oncology at UCSF and served as the founding Deputy Director and Director of Research Programs at the UCSF Helen Diller Family Comprehensive Cancer Center.

doi:10.6004/jnccn.2017.0162

The ideas and viewpoints expressed in this editorial are those of the author and do not necessarily represent any policy, position, or program of NCCN. 